\title{
Regular inhaled $\beta$ agonist in asthma: effects on exacerbations and lung function
}

D R Taylor, M R Sears, G P Herbison, E M Flannery, C G Print, D C Lake, D M Yates, $M$ K Lucas, Q Li fenoterol resulted in more exacerbations, a significant decline in baseline lung function, and an increase in airway responsiveness to methacholine in asthmatic subjects, but did not alter bronchodilator responsiveness. These findings support the previous report that regular inhaled $\beta$ agonist treatment is deleterious in the long term control of asthma.

(Thorax 1993;48:134-138)

Although inhaled $\beta$ agonists provide rapid relief of symptoms of asthma, some studies have suggested that regular use of an inhaled $\beta$ agonist drug may cause a decrease in lung function, ${ }^{12}$ an increase in reactivity to nonspecific bronchoconstrictors such as methacholine, ${ }^{34}$ and rebound airway responsiveness on cessation of $\beta$ agonist treatment. ${ }^{5}$ Other studies have questioned whether chronic $\beta$ agonist treatment may induce tachyphylaxis and reduce the bronchodilator response to supplementary treatment. ${ }^{6-8}$ We recently reported that the clinical control of bronchial asthma was made worse by regular inhalation of the $\beta$ agonist fenoterol bromide. ${ }^{9}$ This paper reports further data from that study related to the clinical course of patients over the full treatment period, including the number and severity of exacerbations, and describes the changes in lung function and in methacholine and bronchodilator responsiveness with time.

\section{Methods}

Details of the trial design, subjects, and methods have been reported. ${ }^{9}$ Briefly, 64 adults (table 1) who had had mild to moderate asthma (not requiring continuous oral corticosteroid treatment) for at least one year

\section{Table 1 Anthropometric data for 64 study subjects}

\begin{tabular}{|c|c|}
\hline $\begin{array}{l}\text { Subjects } \\
\text { Age (y) }\end{array}$ & $\begin{array}{l}28 \text { male, } 36 \text { female } \\
\text { Range } 15-64 \text {, median } 38, \\
\text { mean } 37 \cdot 2\end{array}$ \\
\hline \multicolumn{2}{|l|}{ Smoking state (No): } \\
\hline Non-smokers & $42(66 \%)$ \\
\hline Ex-smokers & $19(30 \%)$ \\
\hline Current smokers & $3(5 \%)$ \\
\hline $\mathrm{FEV}_{1}(\mathrm{l})$ at entry & $\begin{array}{l}2 \cdot 46(95 \% \text { CI } 2 \cdot 25-2 \cdot 67) \\
77 \cdot 0 \% \text { predicted }(95 \% \text { CI } \\
73 \cdot 1-80 \cdot 9)\end{array}$ \\
\hline \multicolumn{2}{|c|}{ Daily inhaled corticosteroid dose (No) } \\
\hline & 14 \\
\hline $150-400 \mu \mathrm{g}$ & 24 \\
\hline $401-800 \mu \mathrm{g}$ & 15 \\
\hline$>800 \mu \mathrm{g}$ & 11 \\
\hline
\end{tabular}
\begin{abstract}
during the period of resures Prebronchodilator forced expiratory volume in one second $\left(F E V_{1}\right)$ was on average 0.15 litres lower $(95 \%$ confidence interval (95\% CI) $0 \cdot 11-0 \cdot 19)$ and vital capacity (VC) 0.12 litres lower (95\% CI 0.08-0.16) than during the placebo period. Morning peak flow rates were significantly lower and evening peak flow rates significantly higher, with an increase in diurnal variation from $9.8 \%(95 \% \mathrm{CI} 6.9-12 \cdot 8)$ to $17.5 \%$ $(95 \%$ CI 13.8-21.3) during regular treatment. Geometric mean concentration of methacholine causing a $20 \%$ fall in $\mathbf{F E V}_{1}$ from the value after saline $\left(\mathbf{P C}_{20}\right)$ decreased significantly from 1.63 to 1.15 $\mathrm{mg} / \mathrm{ml}$, indicating increased bronchial hyperresponsiveness during regular treatment. Response to bronchodilator, as measured by the \% increase in post-

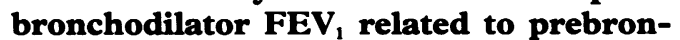
chodilator $F_{E V}$, was maintained with no evidence for tachyphylaxis.

Conclusion Chronic use of inhaled
\end{abstract}


completed a double blind, randomised, placebo controlled cross over study in which for two periods of 24 weeks each, either fenoterol bromide $(400 \mu \mathrm{g})$ or matching placebo was inhaled as a dry powder four times daily. This dose was equivalent to the usual dose of fenoterol given by metered dose inhaler ( 200 $\mu \mathrm{g}$, two puffs four times a day) in New Zealand at that time. Subjects were allowed additional known $\beta$ agonist (fenoterol (29 subjects), salbutamol (33 subjects), or terbutaline (two subjects)) by metered dose inhaler for relief of symptoms as needed. ${ }^{9}$ All other bronchodilators (oral $\beta$ agonists, theophylline, inhaled ipratropium) were required to be withdrawn before entry without compromising lung function. Inhaled corticosteroid was used by 50 of the 64 subjects (dose range 150 to $3000 \mu \mathrm{g}$, median $600 \mu \mathrm{g}$, mean $803 \mu \mathrm{g}$ ) and had been taken in a stable dose for at least three months before the study began; many subjects had used inhaled corticosteroids for years. No change in the maintenance dose was permitted even during exacerbations, which were treated with known $\beta$ agonist by metered dose inhaler as required and, if more severe, by a short standardised course of oral prednisone. ${ }^{9}$

Control of asthma was assessed from daily symptom scores, morning and evening peak flow rates measured by mini-Wright meter, the need for additional inhaled $\beta$ agonist, and for short courses of prednisone. The onset of an exacerbation of asthma was defined as the day of concurrent appearance of two or more of the predetermined criteria listed in table 2 . The duration of an exacerbation was calculated as the days from the onset until symptom scores and peak flow rates returned to the previous baseline. When a return to previous baseline was not achieved, the exacerbation was assumed to have ended when a new stable baseline appeared.

Every four weeks subjects performed spirometry; this was followed by either a methacholine or bronchodilator challenge. The best of at least three acceptable (to within 5\%) vital capacity (VC) and forced expiratory volume in one second $\left(\mathrm{FEV}_{1}\right)$ measurements on a Godart water spirometer were recorded. Methacholine challenge was performed on alternate four-weekly visits by the method of Cockcroft et al. ${ }^{10}$ Bronchodilator responsiveness was assessed on alternate visits by repeating spirometry 10 minutes after administration of nebulised salbutamol $(5 \mathrm{mg} / \mathrm{ml})$ or fenoterol $(5 \mathrm{mg} / \mathrm{ml})$

\section{Table 2 Criteria for an exacerbation}

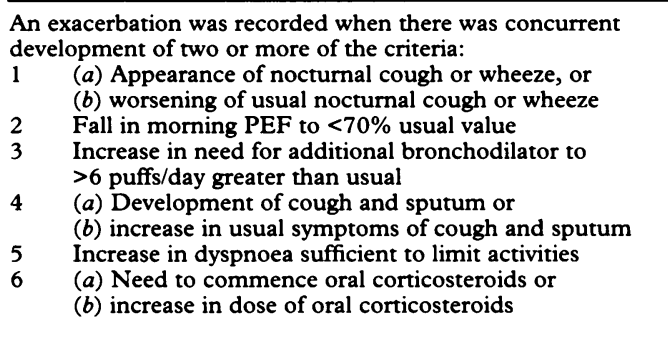

for two minutes. The drug used for each bronchodilator challenge in individual patients was that in the known metered dose inhaler $\beta$ agonist used by that patient. Nebulised $\beta$ agonist was delivered by a Hudson up-draft nebuliser with oxygen at a flow rate of $61 / \mathrm{min}$ delivering $0.13 \mathrm{ml} / \mathrm{min}$; this provided a delivered dose of about $1 \cdot 25$ $\mathrm{mg}$ of either agent. Subjects refrained from using any treatment with inhaled drugs (including the blinded trial medication) for at least six hours before attending the laboratory.

\section{STATISTICAL ANALYSIS}

Observed FEV 1 and VC were compared with predicted values determined for age, sex, and height from formulae for New Zealand caucasians previously reported from our laboratory. ${ }^{11}$ Mean morning and evening peak expiratory flow rates were calculated for each successive four week period. Diurnal variation in peak flow was calculated from the formula:

[(evening-morning PEF)/evening PEF $] \times 100 \%$

Airway responsiveness was measured as the provoking concentration of methacholine $\left(\mathrm{PC}_{20} \mathrm{FEV}_{1}\right)$ that caused a $20 \%$ fall in FEV from the value after saline. ${ }^{10}$ The $\mathrm{PC}_{20}$ values were log transformed for comparisons. Response to bronchodilator was measured as the increment in $\mathrm{FEV}_{1}$ expressed as \% of the prebronchodilator $\mathrm{FEV}_{1}$ :

[(postbronchodilator $\mathrm{FEV}_{1}$ - prebronchodilator $\mathrm{FEV}_{1}$ ) prebronchodilator $\left.\mathrm{FEV}_{1}\right] \times 100 \%$.

Data were analysed with the SSPSX:MANOVA procedure for analysis of variance of repeated measurements, ${ }^{12}$ to identify between treatment differences and treatment-time interactions. Paired survival analysis by the method of Akritis was used to determine the significance of differences in exacerbation rates between treatments. ${ }^{13}$

\section{Results}

Despite instruction not to vary inhaled corticosteroid dose throughout the study, diaries from 11 subjects showed differences in cumulative consumption of inhaled corticosteroid between treatment periods of greater than $5 \%$. Nine of these 11 used more inhaled corticosteroid during the period of active fenoterol treatment. Any bias from this increase in dose should favour a better outcome on regular treatment, but in fact there were more exacerbations of asthma and indices of lung function were lower during regular fenoterol treatment.

Figure 1 shows the number of exacerbations experienced by each subject during each 24 week treatment period. Almost twice as many subjects experienced more than six exacerbations during regular treatment compared with during as needed treatment (17v nine subjects). On the other hand, 25 subjects had no, or only one exacerbation during as needed treatment compared with only 17 during regular treatment. There were 261 exacerbations (mean $4 \cdot 1$ per subject) during 
Figure 1 Number of exacerbations experienced treatment period. by each subject during each

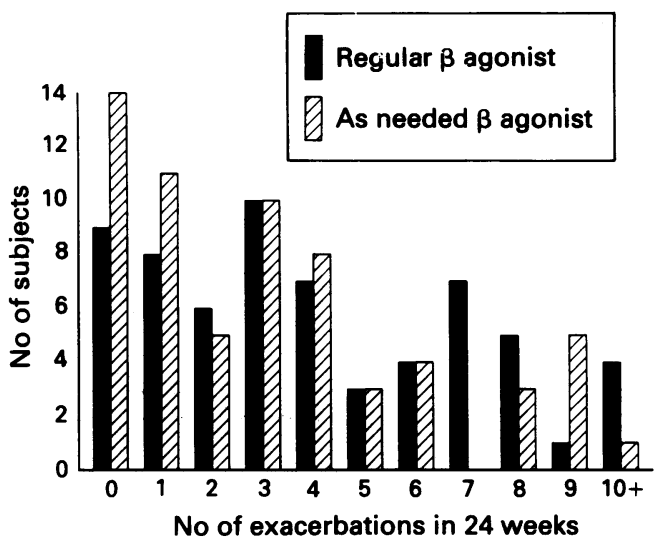

regular treatment, compared with 201 (mean 3.1 per subject) during as needed treatment. Overall, 36 subjects $(56 \%)$ had more exacerbations during treatment with regular $\beta$ agonist compared with 20 subjects $(31 \%)$ with more exacerbations during as needed treatment. These differences in exacerbations between treatment periods did not reach statistical significance.

The median time from the commencement of each treatment period to the first exacerbation was 33 days when on regular treatment compared with 66 days when taking $\beta$ agonist only as needed $(t=2.39, d f=63, p=0.02)$. Separation of the "survival curves" was seen after two weeks (fig 2). At 30 days, 31 subjects had experienced an exacerbation while on regular $\beta$ agonist, compared with 19 on as needed treatment. After 90 days of regular treatment, 51 subjects had had an exacerbation compared with 37 during as needed treatment.

Severe exacerbations requiring admission to hospital occurred in five patients and of these, four occurred during regular fenoterol treatment. All occurred after at least 16 weeks of treatment.

Twenty three subjects required one or more short courses of prednisone during the study. Seventeen patients required prednisone during regular treatment (mean duration 30 days, $95 \%$ confidence interval $(95 \%$ CI) 11-49), and 14 during placebo (mean 24 days, 95\% CI 11-37); eight of these used

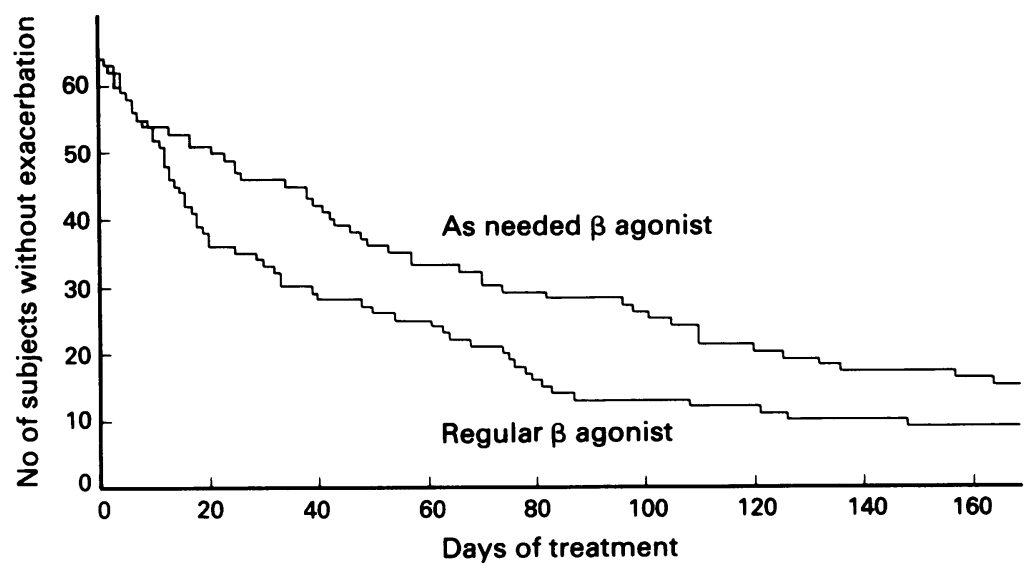

Figure 2 "Survival curve" of subjects not experiencing an exacerbation by duration of treatment period.
Table 3 Mean FEV (l) for 64 subjects during regular and as needed $\beta$ agonist treatment

\begin{tabular}{llll}
\hline & $\begin{array}{l}\text { Regular } \\
\beta \text { agonist } \\
\text { Week }\end{array}$ & $\begin{array}{l}\text { As needed } \\
\beta \text { agonist } \\
\text { Mean }(95 \% \text { CI) }\end{array}$ & Difference \\
\hline 0 & $2 \cdot 41(2 \cdot 21-2 \cdot 61)$ & $2 \cdot 45(2 \cdot 23-2 \cdot 67)$ & $0 \cdot 04$ \\
4 & $2 \cdot 38(2 \cdot 10-2 \cdot 66)$ & $2 \cdot 49(2 \cdot 22-2 \cdot 76)$ & $0 \cdot 11$ \\
8 & $2 \cdot 33(2 \cdot 12-2 \cdot 54)$ & $2 \cdot 62(2 \cdot 36-2 \cdot 88)$ & $0 \cdot 29$ \\
12 & $2 \cdot 38(2 \cdot 09-2 \cdot 67)$ & $2 \cdot 48(2 \cdot 27-2 \cdot 69)$ & $0 \cdot 09$ \\
16 & $2 \cdot 33(2 \cdot 14-2 \cdot 52)$ & $2 \cdot 45(2 \cdot 24-2 \cdot 66)$ & $0 \cdot 12$ \\
20 & $2 \cdot 35(2 \cdot 15-2 \cdot 55)$ & $2 \cdot 46(2 \cdot 26-2 \cdot 66)$ & $0 \cdot 11$ \\
24 & $2 \cdot 30(2 \cdot 09-2 \cdot 51)$ & $2 \cdot 46(2 \cdot 26-2 \cdot 66)$ & $0 \cdot 17$ \\
\multicolumn{2}{l}{ Mean difference } & & $0 \cdot 15$ \\
\hline
\end{tabular}

$p<0.005$ for difference in treatment effect on absolute FEV $_{1}$.

prednisone during both periods. These differences in use of prednisone were not statistically significant. Significant individual between treatment differences in use of prednisone occurred, however, in 19 patients, of whom 11 required more prednisone during regular $\beta$ agonist treatment.

Mean prebronchodilator $\mathrm{FEV}_{1}$ was significantly lower $(0.151, \mathrm{p}<0.005)$ at all time points during regular fenoterol treatment compared with as needed treatment (table 3 ). There was no time treatment interactionthat is, $\mathrm{FEV}_{1}$ was lower during regular treatment but did not deteriorate further after the first four weeks of treatment. Vital capacity was also significantly lower $(0.121, p<$ 0.01 ), during regular treatment. There was a significant time-treatment interaction on VC during both regimens $(p<0.001)$, but the slight downward slope did not differ between regimens $(p=0.33)$.

Table 4 shows the increases in $\mathrm{FEV}_{1}$ after nebulised bronchodilator at baseline and at eight week intervals throughout the study. Differences in response between treatments were not significant.

Figure 3 shows mean morning and evening peak flow rates calculated for each four-week interval during the study. Morning peak flow rates were consistently higher during the period of as needed bronchodilator treatment ( $p$ $<0.003)$. There was no significant change with time after week eight. Evening peak flow rates were significantly higher during treatment with regular fenoterol ( $p<0.0005)$; this effect was noted immediately. The overall mean morning peak flow was $402 \mathrm{l} / \mathrm{min}$ during as needed treatment compared with 392 $1 /$ min during regular treatment. The evening values were $432 \mathrm{l} / \mathrm{min}$ and $446 \mathrm{l} / \mathrm{min}$ respectively. The slight downward trends in peak flows with time during regular treatment and

Table 4 Bronchodilator responsiveness expressed as increase in $F E V_{1}$ as \% prebronchodilator FEV, by treatment regimen

\begin{tabular}{lll}
\hline Week & $\begin{array}{l}\text { Regular } \\
\text { Bagonist } \\
\text { Mean }(95 \% \text { CI) }\end{array}$ & $\begin{array}{l}\text { As needed } \\
\beta \text { agonist } \\
\text { Mean }(95 \% ~ C I)\end{array}$ \\
\hline 0 & $29 \cdot 3(23 \cdot 5-35 \cdot 1)$ & $27 \cdot 0(20 \cdot 3-33 \cdot 7)$ \\
4 & $30 \cdot 9(23 \cdot 8-38 \cdot 0)$ & $27 \cdot 5(21 \cdot 6-33 \cdot 4)$ \\
12 & $30 \cdot 1(23 \cdot 4-36 \cdot 9)$ & $26 \cdot 7(21 \cdot 7-31 \cdot 7)$ \\
20 & $26 \cdot 6(21 \cdot 4-31 \cdot 8)$ & $27 \cdot 3(22 \cdot 1-32 \cdot 4)$ \\
\hline
\end{tabular}

Differences between treatments are not significant. 


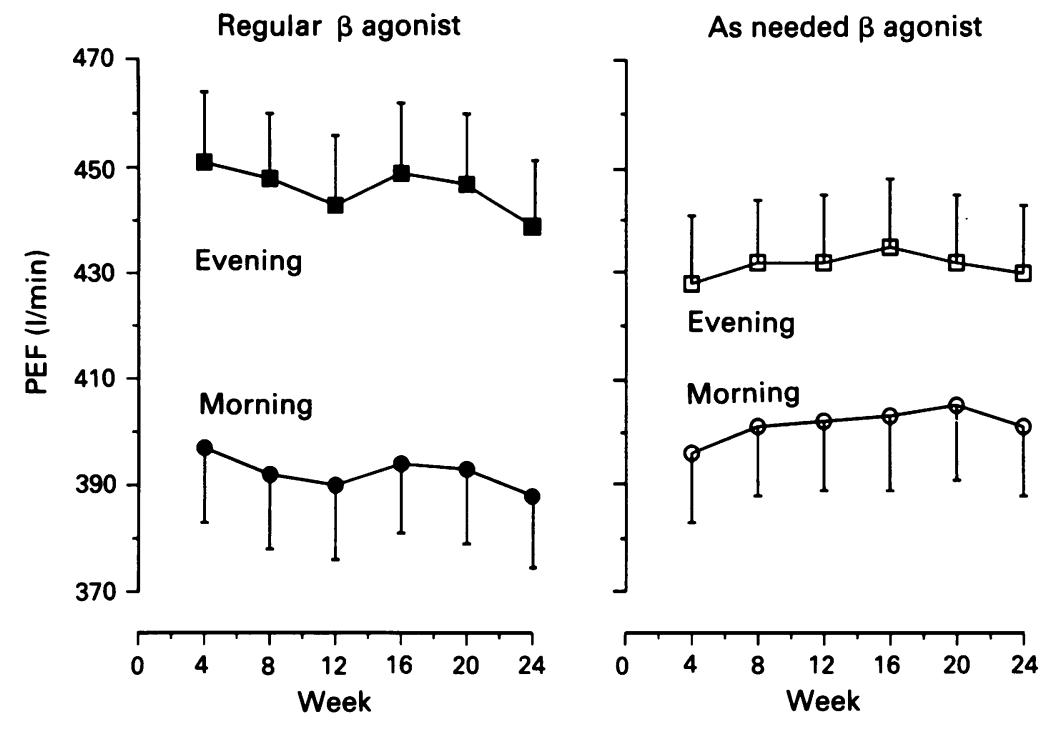

Figure 3 Mean morning and evening peak flow rates (with standard error bars) during regular and as needed $\beta$ agonist treatment, averaged over each four week period.

slight upward trends during as needed treatment (fig 3) were not statistically significant. The diurnal variation in peak flow rate increased significantly from $9 \cdot 8 \%(95 \% \mathrm{CI}$ 6.9-12.8) during as needed bronchodilator treatment to $17 \cdot 5 \%(95 \% \mathrm{CI} 13 \cdot 8-21 \cdot 3)$ during regular bronchodilator treatment $(\mathrm{p}<0.0005)$.

Table 5 gives the geometric mean data for measurements of airway responsiveness at baseline and at weeks eight, 16, and 24 of each treatment period. Geometric mean $\mathrm{PC}_{20}$, although variable, was consistently lower during regular $\beta$ agonist treatment (airway responsiveness was greater). Although the overall mean $\mathrm{PC}_{20}$ was only a half concentration lower during regular treatment $(1 \cdot 15$ compared with $1.63 \mathrm{mg} / \mathrm{ml}$ during as needed treatment), the difference at each period was highly significant $(p=0.003)$ There was no significant time trend $(p=0 \cdot 12)$.

\section{Discussion}

These results supplement those reported earlier, ${ }^{9}$ and are consistent with the conclusion that control of bronchial asthma is worse when a $\beta$ agonist bronchodilator is inhaled regularly. In our earlier report, assessment was based on intraindividual comparisons of markers of asthma control in the last 16

Table 5 Airway responsiveness to methacholine by time and treatment regimen

\begin{tabular}{lll}
\hline Week & $\begin{array}{l}\text { Regular } \\
\beta \text { agonist } \\
\text { Mean* }(95 \% \text { CI })\end{array}$ & $\begin{array}{l}\text { As needed } \\
\beta \text { agonist } \\
\text { Mean }\end{array}$ \\
\hline 0 & $1.19(05 \%$ CI $)$ \\
8 & $0.98(0.70-1.63)$ & $1.34(1.01-1.77)$ \\
16 & $1.05(0.73-1.51)$ & $1.48(1.02-2.15)$ \\
24 & $1.46(1.09-1.96)$ & $1.46(0.95-2.24)$ \\
Overall & 1.15 & $2.00(1.45-2.75)$ \\
\hline
\end{tabular}

*Geometric mean

Differences in $\mathbf{P C}_{20}$ between treatments highly significant $(p=0.003)$ at each interval. weeks of each treatment period after allowing an eight-week washout period. In this paper clinical and physiological measurements are analysed as mean group data for the entire 24 weeks of each period.

It proved difficult to precisely quantify the duration of asthma exacerbations in this study, despite the prospective use of predetermined criteria. Whereas the onset of an exacerbation was readily determined, the end was less clear, especially if a return to former baseline measurements of morning peak flow or symptom state was not achieved. If the baseline state deteriorated, then the time for recovery after an exacerbation to a new (worse) baseline would be shorter than if the episode were recorded as persisting until the original baseline values were recovered. In some instances this would never have been achieved. Hence we may have underestimated the duration of some exacerbations, particularly during regular treatment when baseline shifts were more evident, as seen in the pulmonary function data. Despite this, we found that more subjects experienced more exacerbations during the period of regular fenoterol treatment, and the median time to the first exacerbation was significantly shortened during regular treatment compared with as needed treatment.

The decreases in prebronchodilator $\mathrm{FEV}_{1}$ and in morning peak expiratory flow rates, together with the increase in diurnal variation of peak flow rates, were all highly significant. Increased diurnal variation was attributable in part to the acute bronchodilator effect during the period of regular treatment giving an increased evening peak flow rate, and also to a consistently lower morning peak flow rate during regular treatment. This suggests that, when the acute bronchodilator action of fenoterol waned, baseline bronchoconstriction increased.

This phenomenon of rebound bronchoconstriction (that may in part explain the overall adverse effect of regular treatment with bronchodilator) has been found previously in association with the use of high doses of isoprenaline. ${ }^{1415}$ Rebound bronchoconstriction may also explain why subjects found it necessary to continue to use supplementary bronchodilator during fenoterol treatment (mean 2.45 puffs per day, (95\% CI $2 \cdot 15-2 \cdot 75)$ ). The retention of a normal response to acute administration of $\beta$ agonist may explain why patients and physicians alike have not recognised the adverse effects of chronic $\beta$ agonist treatment. As measured by a conventional reversibility test, there was no evidence of tachyphylaxis. Likewise the relevance of the small decline in prebronchodilator $\mathrm{FEV}_{1}$ is unlikely to be recognised if postbronchodilator values are undiminished.

Decreases in lung function during regular treatment with fenoterol have been reported by others. Trembath et al ${ }^{16}$ showed that FEV fell from a mean value of $2 \cdot 76$ to 2.43 litres $(\mathrm{p}<0.05)$ in 15 asthmatic subjects treated with inhaled fenoterol for four weeks. Van Arsdel et al ${ }^{17}$ recorded a fall in $\mathrm{FEV}_{1}$ from 
2.53 to 2.05 litres in 13 subjects treated for 12 weeks with oral fenoterol. Such effects have also been found using $\beta$ agonists other than fenoterol. Harvey and Tattersfield gave atopic non-asthmatic and atopic asthmatic subjects inhaled salbutamol in increasing doses from $100 \mu \mathrm{g}$ four times daily in week 1 to $500 \mu \mathrm{g}$ qid in week $4 .^{\prime}$ There were significant falls in $\mathrm{FEV}_{1}$ of 0.35 litres in the asthmatic group, and 0.24 litres in the non-asthmatic group. More recently, use of regularly inhaled salbutamol by asthmatic patients for four months was associated with a significant $(p<0.0001)$ fall in $\mathrm{FEV}_{1}$ from $79 \%$ to $76 \%$ predicted. ${ }^{18}$

This study confirms previous reports that regular $\beta$ agonist treatment results in a small but significant increase in airway responsiveness to non-specific challenge. ${ }^{34}$ Van Schayck and colleagues found a similar significant reduction in $\mathrm{PC}_{20}$ in subjects with chronic bronchitis or asthma given regular salbutamol for one year. ${ }^{3}$ In shorter studies, both Kraan et $a l^{4}$ and Kerrebijn et al ${ }^{19}$ found that methacholine or histamine responsiveness increased slightly during regular terbutaline treatment by contrast with the decreased responsiveness seen during regular inhaled corticosteroid treatment.

The changes in airway responsiveness that occur with regular $\beta$ agonist treatment are small, and are considerably less than the two to fourfold reductions in responsiveness that have been described during inhaled corticosteroid treatment. ${ }^{2021}$ Nevertheless, increased airway responsiveness is a consistent finding irrespective of the $\beta$ agonist used. Although the magnitude of these changes in $\mathrm{PC}_{20}$ and $\mathrm{FEV}_{1}$ may seem to be small and of little significance in any one patient, they are highly significant in populations of asthmatic patients. The epidemiological impact of such changes has been discussed by Mitchell, ${ }^{22}$ who argued how a small shift in mean $\mathrm{PC}_{20}$ for an asthmatic population (whether due to regular $\beta$ agonist treatment or to other causes) could explain an increase in the prevalence of more severe disease, and the gradually worsening morbidity and mortality from asthma evident worldwide. ${ }^{23} 24$

In summary, the occurrences of exacerbations and changes in lung function and nonspecific airway responsiveness that we have recorded during 24 weeks of treatment with regular fenoterol compared with placebo are consistent with physiological changes identified in other investigations, and correlate with the deterioration in overall control of bronchial asthma that we previously reported. ${ }^{9}$ These findings reinforce recommendations that short acting, agonists should not be used for regular maintenance treatment in asthma. At the very least, they add to a growing body of evidence indicating that regular long term treatment with inhaled bronchodilators confers no significant benefit on lung function, and may in fact be deleterious.
This study was funded by the Medical Research Council of New Zealand, with supplementary grants from Astra (Pharmaco, NZ) and Fisons (NZ). Active fenoterol, placebo, and inhalators were supplied by Boehringer Ingelheim (NZ) Inc.

1 Harvey JE, Tattersfield AE. Airway response to salbutamol: effect of regular salbutamol inhalations in normal, atopic, and asthmatic subjects. Thorax 1982;37:280-7.

2 van Schayck CP, Dompeling E, van Herwaarden CLA Folgering $\mathrm{H}$, Verbeek ALM, van den Hoogen HJM, et al. Long-term effects of continuous versus symptomatic bronchodilator treatment in patients with moderate asthma or chronic bronchitis. BMf 1991;303:1426-31.

3 van Schayck CP, Graafsma SJ, Visch MB, Dompeling E, van Weel C, van Herwaarden CLA. Increased bronchial hyperresponsiveness after inhaling salbutamol during 1 hyperresponsiveness after inhaling salbutamol during 1 year is not caused by subsensitization
Allergy Clin Immunol 1990;86:793-800.

4 Kraan J, Koeter GH, v d Mark ThW, Sluiter HJ, de Vries $\mathrm{K}$. Changes in bronchial hyperreactivity induced by 4 weeks of treatment with antiasthmatic drugs in patient with allergic asthma: A comparison between budesonide and terbutaline. $\mathfrak{f}$ Allergy Clin Immuno 1985;76:628-36.

5 Vathenen AS, Knox AJ, Higgins BG, Britton JR, Tattersfield AE. Rebound increase in bronchial responsiveness after treatment with inhaled terbutaline. Lancet 1988;i:554-8.

6 Lipworth BJ, Clark RA, Dhillon DP, McDevitt DG Subsensitivity of $\beta$-adrenoceptor responses in asthmatic pubsensitivity of $\beta$-adrenoceptor responses in asthmatic patients taking regular low dose

7 Tashkin DP, Conolly ME, Deutsch RI, Hui KK, Littne $\mathrm{M}$, Scarpace $\mathrm{P}$, et al. Subsensitization of $\beta$-adrenoceptors in airways and lymphocytes of healthy and asthmatic subjects. Am Rev Respir Dis 1982;125:185-93.

8 Weber RW, Smith JA, Nelson HS. Aerosolized terbutaline in asthmatics: development of subsensitivity with longterm administration. F Allergy Clin Immunol 1982;70: 417-22.

9 Sears MR, Taylor DR, Print CG, Lake DC, Li Q Flannery EM, et al. Regular inhaled $\beta$-agonist treatment in bronchial asthma. Lancet 1990;336:1391-6.

10 Cockcroft DW, Killian DN, Mellon JA, Hargreave FE Bronchial reactivity to inhaled histamine: a method and clinical survey. Clin Allergy 1977;7:235-43.

11 Sinclair SW, Avery SF, Brady DM, Smith DA, Holst PE O'Donnell TV. Prediction formulae for normal pulmonary function values in New Zealand European subjects. NZ Med f 1980;91:1-5.

12 Norusis MJ. In: SPSS Advanced statistics guide. Chicago: SPSS Inc, 1985.

13 Woolson RF, O'Gorman TW. A comparison of several tests for censored paired data. Stat Med 1992;11: 193-208.

14 Reisman RE. Asthma induced by adrenergic aerosols. $f$ Allergy 1970;46:162-77.

15 Keighley J. Iatrogenic asthma associated with adrenergic aerosols. Ann Intern Med 1966;65:985-95.

16 Trembath PW, Greenacre JK, Anderson M, Dimmock S, Mansfield L, Wadsworth J, et al. Comparison for four weeks' treatment with fenoterol and terbutaline aerosols in adult asthmatics. A double-blind crossover study. $\mathscr{f}$ Allergy Clin Immunol 1979;63:395-400.

17 VanArsdel PP, Schaffrin RM, Rosenblatt J, Sprenkle AC, Altman LC. Evaluation of oral fenoterol in chronic asthmatic patients. Chest 1978;73:997-8

18 van Essen-Zandvliet EEM, Waalkens HJ, Duiverman EJ Hughes $\mathrm{MD}$, Kerrebijn $\mathrm{KF}$, and the Dutch CNSLD study oroup Long term intervention in children with study gr. Influence on airway calibre and airway hyp with sponsiveness. Am Rev Respir Dis 1991;143:A421.

19 Kerrebijn KF, van Essen-Zandvliet EEM, Neijens HJ. Effect of long-term treatment with inhaled corticosteroids and $\beta$-agonists on the bronchial responsiveness teroids and $\beta$-agonists on the bronchial responsiveness in children with

20 Juniper EF, Kline PA, Vanzieleghem MA, Hargreave FE. Reduction of budesonide after a year of increased use: a randomized controlled trial to evaluate whethe improvements in airway responsiveness and clinical asthma are maintained. $\mathcal{f}$ Allergy Clin Immuno 1991;87:483-9.

21 Dutoit JI, Salome CM, Woolcock AJ. Inhaled corticosteroids reduce the severity of bronchial hyperresponsiveness in asthma but oral theophylline does not. Am Rev Respir Dis 1987;136:1174-8.

22 Mitchell EA. Is current treatment increasing asthma mortality and morbidity? Thorax 1989;44:81-4.

23 Anderson HR. Increase in hospital admissions for childhood asthma: trends in referral, severity, and readmissions from 1970 to 1985 in a health region of the sions from 1970 to 1985 in a health

24 Jackson R, Sears MR, Beaglehole R, Rea $H H$ International trends in asthma mortality: 1970 to 1985 Chest 1988;94:914-8. 